\title{
Article
}

\section{What do participants perceive as the attributes of a good adventure sports coach?}

Eastabrook, Chris and Collins, Loel

Available at http://clok.uclan.ac.uk/31876/

Eastabrook, Chris ORCID: 0000-0003-0697-8002 and Collins, Loel ORCID: 0000-0002-7478-1140 (2021) What do participants perceive as the attributes of a good adventure sports coach? Journal of Adventure Education and Outdoor Learning, 21 (2). pp. 115-128. ISSN 1472-9679

It is advisable to refer to the publisher's version if you intend to cite from the work. http://dx.doi.org/10.1080/14729679.2020.1730207

For more information about UCLan's research in this area go to http://www.uclan.ac.uk/researchgroups/ and search for < name of research Group>.

For information about Research generally at UCLan please go to http://www.uclan.ac.uk/research/

All outputs in CLoK are protected by Intellectual Property Rights law, including Copyright law. Copyright, IPR and Moral Rights for the works on this site are retained by the individual authors and/or other copyright owners. Terms and conditions for use of this material are defined in the policies page.

\section{CLoK}

Central Lancashire online Knowledge www.clok.uclan.ac.uk

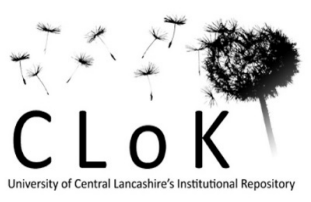


1 For JAEOL

2 APA $6^{\text {th }}$ throughout expect headers where article follows journal guidelines

3 English, use throughout

4

5

6

7

What do Participants Perceive as the Attributes of a Good Adventure Sports Coach?

8

Chris Eastabrook $^{1}$ and Loel Collins ${ }^{1 \& 2}$

9

10

11

12

13

14

1. Institute for Coaching and Performance, University of Central Lancashire, Preston,

15 UK

16

2. Plas y Brenin, National Outdoor Centre, Capel Curig, Gywnedd

17

18

19

$20 *$ Correspondence concerning this article should be addressed to Chris Eastabrook, Institute

21 for Coaching and Performance, University of Central Lancashire, Preston, UK, PR1 2HE.

22 CEastabrook1@uclan.ac.uk 


\section{Abstract}

This paper presents a mixed-method investigation of client's perceptions of a good adventure sports coach. Semi-structured interviews were analysed thematically, and the findings used to inform a subsequent larger survey that sought to verify the importance of the themes identified in the interviews. The findings draw an alignment between the attributes of good coaches in traditional sports, as reported in previous studies, and those of adventure sports coaches. However, they also identify three additional attributes that are critical for good adventure sports coaches: (1) in-depth knowledge of the adventure sports environment, (2) a very high degree of individualisation, and (3) an explicit focus on developing the participant's confidence. The implications for training adventure sports coaches are discussed. Keywords: adventure sports coaching, coach's attributes, coach's knowledge, individualisation, self-efficacy 
Adventure sports are growing in popularity (O’Keefe, 2019), consequently there has

been an increase interest in understanding coaching practice in this domain. However, much of the research investigating adventure sports coaching has relied upon the self-reporting of highly experienced and qualified coaches (e.g., Christian, Berry, \& Kearney, 2017; Collins \& Collins, 2015; Collins, Carson, \& Collins, 2016). Similarly, Becker (2009) reports that the majority of coaching research explores the effectiveness of coaching rather than the characteristics of the coach themselves. Becker reports six dimensions of great coaching; coach attributes, the environment, relationships, the system, coaching actions, and influences. And states 'Great coaches [are not only coaches], but extraordinary people who left lasting impressions on the lives' on those they coach (p. 112). Reflecting the potential impact of coaches and the impact of adventurous environments on individuals (Mackenzie \& Brymer, 2018), it seems sensible to extent Becker's investigation into adventure sports coaching. Additionally, to understand adventure sports coaching practice from a different perspective, we previously investigated what participants sought from their coaching experience (Eastabrook \& Collins, 2019) and reported that participants were unable to separate coaches' attributes from the coaching process. Consequently, there are three aspects of this this study; (1) reflecting on the participants' lack of perceived separation, it seems logical to further investigate what good coaching is in the adventure domain, (2) to continue our original line of investigation into adventure sport coaching from the perspective of participants rather than coach and, (3) to extend and narrow the remit of Becker's investigation into adventure sports

61 coaching. We expand our earlier study to ask a group of adventure sport coaching

62 participants, What are the attributes of a good adventure sports coach? With the aim to

63 inform and improve adventure sports coach training and education. We first explore the 
attributes of good coaches in both traditional and adventure sports as reported in previous studies.

\section{Review of existing literature}

Many authors (e.g., Becker, 2009; Cassidy, Jones, \& Potrac, 2009; Côté \& Gilbert, 2009; Côté \& Sedgwick, 2003; Light \& Evans, 2013; Nash, Martindale, Collins, \& Martindale, 2012; Weiss, Barber, Sisley, \& Ebbeck, 1991) have discussed the characteristics of good coaches and offered numerous perspectives of what constitutes good coaches in a range of sports. Commonly, these characteristics include having excellent subject knowledge and interpersonal, pedagogic, leadership, and management skills.

\section{Coaches' knowledge}

Côté, Saimela, Trudel, Baria, and Russell (1995) have highlighted the value placed on declarative knowledge by a group of expert gymnastic coaches. This contrasts with Saury and Durand (1998), who suggest that an experienced coach has access to implicit knowledge as 'professional know-how' (p. 264). As Sinfield, Allen, and Collins (2019) recognise, the reality entails a synergy of both declarative and implicit knowledge to achieve the adaptive coaching required in the adventure context. This aligns with the findings of Collins and Collins (2016a, 2016b) and Tozer, Fazey, and Fazey (2007) regarding adaptive requirements.

Both sets of authors describe adaptability and flexibility as key attributes of high-level adventure sports coaches, and suggest this is a response to the situational demands created by a hyper-dynamic coaching environment and the complexity of the individual being coached (Collins \& Collins, 2015; Collins \& Collins, 2016a). Fluid notions of knowledge and expertise seem to be integral to the practices of the coach in adventure sports. Collins, Collins, \& Carson (2016) exemplify this as 'knowledge made usable and reliable in context by it becoming tacit following a period of reflection on extensive experience' (p. 5). Indeed, 
knowledge gathered from experience via reflection is critical in this regard and is logically developed through interaction with clients, understanding their developmental needs and wants, and a close rapport with them.

The high value of knowledge constructed from reflection on experience may, in part, explain why coaches have been found to see little value in formal coach education as reported by Nelson, Cushion, and Potrac (2006). Similarly Sinfield et al. (2019) argue that more experienced coaches may actually benefit from formalised education because their experience brings context to their training. Therefore, and in agreement with Stoszkowski and Collins (2012), it seems necessary to include the reflective skills needed to make sense of lived experiences in coach education. Such approaches clearly help to create the 'lifelong learners committed to personal growth' (p. 221) highlighted by Côté (2006) as a key attribute of effective coaches. Lifelong learning within the adventure coaching sector aligns with the sophisticated epistemological position high-level adventure sport coaches hold (Christian, Hodgson, Berry, \& Kearney, 2019, Collins \& Collins, 2016a). This sophisticated position adds a depth and complexity to the adventure sport coaches knowledge.

\section{Coaches' interpersonal skills}

At the heart of the coach-athlete relationship are coaches' interpersonal skills. Lafrenière, Jowett, Vallerand, and Carbonneau (2011) describe the relationship between coaches and athletes as one marked by interdependence. In practical terms and particularly pertinent is this interdependence in adventure sports, adventure sports coaches and clients undertake the activity together (Collins \& Collins, 2012). Coaching poses an inherent challenge for the coach, who must manage the process with, and for the participant (Buckley, 2012; Pomfret \& Bramwell, 2016). Coaches must consider, for example, the difficulty of a task (e.g., chosen climbing route), the influence of the environment (e.g., sea state), or 
112 psychosocial factors (e.g., peer pressure) on the participant while measuring the effectiveness

113 of the coaching relationship. This interdependence requires a two-way flow of information

114 and trust, whereby coaches set appropriate goals for clients and support them to achieve those

115 goals. Mageau and Vallerand (2003) have termed such behaviour as autonomy supportive.

116 Additionally, the social aspect of adventure sports is recognised as important by Kerr

117 and Mackenzie (2012) and Mackenzie and Brymer (2018). The coach accompanies the client

118 on the adventure, a friendly demeanour and rapport with the client in challenging situations

119 project a positive attitude toward goal achievement (Ianiro, Lehmann-Willenbrock, \&

120 Kauffeld, 2015). Likewise, Gray and Collins (2016) report the interpersonal strategies used

121 by adventure sports coaches, including intuitive social engagement, though they suggest this

122 is not used at a strategic level. In team sports, Gearity (2012) reports how interpersonal skills

123 and social engagement can be used to create a positive coaching environment, highlighting a

124 link to the coach's teaching ability.

\section{Coaches' teaching and pedagogical skills}

Gearity (2012) states that coaches should be 'knowledgeable of the technical, tactical,

127 and mental skills of their sport and also how to facilitate athletes' learning' (p. 91), namely a

128 declarative knowledge of the activity and also the pedagogic and andragogic skills required to

129 facilitate development. Particularly within adventure sports coaching, coaches face the

130 complexities of individual motivations and hyper-dynamic environmental pressures (Collins

$131 \&$ Collins, 2016a). Adventure sports coaches have developed multiple approaches to facilitate

132 effective learning in a variety of contexts (Collins et al., 2016), which may be illustrative of

133 the sophisticated epistemological position (Schommer, 1994) that has been identified in high-

134 level adventure sports coaches (Christian et al., 2017). This sophistication is reflected in the

135 ability to utilise different approaches rather than a fixed didactic approach. 
137 adventure sports coaches to individualise the coaching process (Christian et al., 2017; Collins

138 et al., 2015). However, it remains unclear what is being individualised. For instance,

139 adventure sports coaches are expected to make decisions on the teaching approach as well as

140 the technical skills to be taught in response to students' learning needs (Collins \& Collins,

141 2016b). A focus on the students' learning needs is, potentially, in contrast to that of

142 traditional sports coaching. Bloom, Crumpton, \& Anderson (1999) identified that expert

143 basketball coaches spent $60 \%$ of their time teaching the technical and tactical aspects of their

144 game. This difference in focus may reflect the stated aims of adventure sports coaches to

145 develop fully independent performance in their adventure sports students.

\section{Management and leadership skills}

The importance of management and leadership for sports coaches is highlighted by

148 Sage (1973), who suggests that the two are synonymous in this context. While athletes look

149 to each other for social trends and team goals, they seek advice from their coaches for

150 leadership and management relating to physical ability and goal attainment (Price \& Weiss,

151 2013). Both Price and Weiss (2013) and Vella, Oades, and Crowe (2012) propose

152 transformational leadership as a structure for achieving good leadership because it fosters

153 confidence and character development. More contextually, however, McElligott (2015)

154 reports the use of both rewards for meeting specific goals, i.e. rest day after summit, and

155 developing their intrinsic motivation to reach the summit. These two approaches are

156 characterised by McElligott as transactional and transformational leadership, hinting at the

157 sophisticated epistemology identified earlier with regard to approach.

\section{$158 \quad$ Perceptions of adventure sports coaching recipients}


160 motivations to participate in adventure sports are multifaceted (Kerr \& Mackenzie, 2012) and

161 complex (Collins \& Brymer, 2018), and consequently the perceptions of good coaching may

162 also differ, such as those reported by Ojala and Thorpe (2015) in Finnish snowboarders.

163 More fundamentally, however, Black and Weiss (1992) suggest there is a potential inherent

164 flaw in investigating client or athlete perspectives. Coaches who are perceived by athletes to

165 give more information and praise following desirable performances scored higher on the

166 measures of perceived success and competence. This may challenge the adventure sports

167 coach who may use bandwidth feedbacking, for instance, in order to develop independence

168 and lifelong learning in a participant. Such approaches may not be considered as good by the

169 participant but do reflect the coach's epistemological position. The potential epistemology

170 misalignment could lead to miscomprehension for both coach and client where the participant

171 perceive they are receiving poor coaching but might actually be taught towards a different

172 motivation for participation.

173 Consequently, understanding what participants perceive as good coaching would 174 appear critical if adventure sports coaches are to be perceived as competent, professional, 175 effective, and offering value for money.

\section{Methodology} adopted. Part 1 was a thematic analysis of semi-structured interviews with a small sample size $(n=15)$, which was then used to inform Part 2, a web-based descriptive design survey

180 (Dunlock, 1993) with a larger sample size $(\mathrm{n}=202)$.

\section{Part 1: Qualitative phase}


184 a high-level adventure sports coach with ten years' experience working across the UK and

185 Europe. The second author is a highly experienced adventure sport coach with over thirty

186 years of experience coaching in the UK and Europe. Both authors take a pragmatic and

187 subjective epistemological position, one that acknowledges multiple interpretation of reality

188 rather than a grand single theory as such we seek a probable truth rather than generalizable

189 findings.

Participants

The study participants were recruited in a stratified random representative sample $(\mathrm{n}=$ 15) against the following criteria: (1) being an adventure sport participant, (2) undertaking a

five-day coached adventure sports programme, and (3) openness and willingness to engage in

194 the research. The sample was representative and reflected gender and age (female $n=6$, male

$195 \mathrm{n}=9$, mean age $=43$ ), and predominantly activities (mountaineering and rock climbing; $\mathrm{n}=$

19611 and canoeing and kayaking; $\mathrm{n}=4)$.

197 Data collection

Participants were invited to consider their participation at the start of their coaching programme and were provided with an information sheet. Following agreed consent, semistructured interviews were conducted face-to-face in a comfortable and convenient location at the end of the programme or via Skype (Deakin \& Wakefield, 2014) within five days of the programme end. Interviews were conducted over the autumn, winter, and spring of 2017-18.

203 The interviews adopted an informal approach following the interview guide found in Table 1 and aimed to expose unanticipated themes and develop a better understanding of the responses to the questions (Zhang \& Wildemuth, 2006). Participants were asked to recall their recent coaching experience and encouraged to articulate the characteristics of the 
207 particular coach who facilitated that experience. Interviews notes were made during the 208 recording in the form of bracketing (Ahern, 1999), and keep for consideration during later

209 analysis. All interviews were recorded digitally for transcription. This structure was

210 cognitively piloted before use with a smaller representative sample $(n=2)$ with 2 adjustments

211 made to the structure and 11 changes to language made prior to use (Drennan, 2003).

Insert table 1 close to this point.

213 Analysis

Interviews were transcribed verbatim and reviewed for accuracy by checking against

215 the digital recording (Braun \& Clarke, 2012; Fereday \& Muir-Cochrane, 2006). The

216

transcripts were then 'codified while listening to the original recording' (J. A. Smith, Larkin,

\& Flowers, 2009, p. 82) and a thematic analysis was subsequently conducted (Fereday \&

218 Muir-Cochrane, 2006). Initial coding of responses was conducted in three cycles to gain

219 saturation from different perspectives, before grouping into low-order themes. Once convergence was found, the process was repeated to gain mid-order themes. This procedure

221 allowed the data to be compared with existing concepts while remaining open to the recognition and comprehension of new themes (Braun \& Clarke, 2012). The significance of themes was not solely attributed to frequency but also to the emphasis derived from annotations taken during the interview.

\section{Part 2: Quantitative phase}

Following the interviews, a survey was conducted to assess the views of a larger sample who had received adventure sports coaching. The aim was to improve the reliability of the findings from Part 1. Zohrabi (2016) suggested researchers 'should try to involve most participants in all phases of inquiry' (p. 259) to utilise the benefits of member checking

230 (Lincoln \& Guba, 2005). The use of member checking in this matter reflects the concerns of 
231 Smith and McGannon (2018) and has the aim of seeking confirmation from the same

232 population rather than the individual interviewee. The subsequent question was 'How

233 important are the attributes identified in Part 1 to a broader population?'

234 Participants

A convenient, self-selecting sample was utilised with the same criteria as Part 1.

236 Respondents were asked to complete an online survey over the summer of 2018. The link

237 was shared across eight outdoor sport communities on social media, for example, Rock

238 Climbers UK and 'Slightly' White Water Kayaking. This resulted in a total of 250 responses,

239 of which 202 were considered acceptable. Incomplete surveys were rejected, with a

240 completion rate of $81 \%$. The self-selecting nature of this sample differed from the

241 demographics in Part 1, with female participants $(n=78,38 \%)$ sampling higher and water-

242 based activities $(\mathrm{n}=134,66 \%)$ dominant.

243 Data collection

The two high-order themes identified in Part 1 informed the questions in the survey design. The mid-order themes acted as the focus for the sub-questions, and alterations to

246 language were made to improve accessibility and understanding. A point allocation method

247 was used as described by Doyle, Green and Bottomley (1997), where respondents were asked

248 to weigh the importance of each mid-order theme by dividing 100 points between all the mid-

249 order themes (respondents had to use all 100 points). For example, a question with three sub-

250 questions could be 98, one, and one, or 33, 33, and 34, depending on the respondent's feeling.

251 This allocation of points had two advantages. Firstly, it encouraged the respondents to

252 consider the mid-order themes carefully, addressing survey fatigue (Sinickas, 2007) by

253 utilising an alternative to the commonly used Likert scales. Secondly, Part 2 aimed to

254 understand the relative importance of the mid-order themes to inform the comprehension of 
the high-order themes. Doyle et al. discuss the advantages of ranking and points allocation and, although Doyle et al. report ranking as preferred by users because it required less cognitive effort, this is the reason points allocation was used here: to make the respondents think. A cognitive pilot was also applied to a representative sample $(n=6)($ Drennan, 2003) and the language refined as a result. An incentive in the form of a chance to win a shopping voucher was offered for completing the survey with the winner being randomly selected.

Analysis

A simple descriptive statistical analysis was applied to show the mean, standard deviation, and skew for each question.

\section{Results and discussion}

\section{Part 1}

The thematic analysis of the transcripts found 243 codified units. These were subsequently grouped into ten mid-order themes and two high-order themes, as shown in Table 2. The two high-order themes are coaching behaviours and the capacity to adapt. Insert table 2 close to this point.

Part 2 the relative importance of each mid-order theme within each high-order theme. To give the results the most meaning, the two parts have been integrated within the discussion to give each mid-order theme a sense of relative importance within the two high-order themes. 
278 Gemma spoke about 'feeling that the coach gives you the confidence to explore', referring to

279 the exploration of new experiences as well as her abilities. This attribute of coaching

280 behaviour is the most prominent, with 141 respondents in Part 2 giving it the highest value

$281(\mathrm{~m}=24.9)$. The coaches' role in supporting the development of their clients' confidence took

282 three forms - verbal reassurance, personal accomplishments, and vicarious experiences - and

283 possibly reflects the risks associated with adventure sports participation. Bandura's (1977)

284 work on self-efficacy supports the existence of these roles, noting that personal

285 accomplishments are a stronger source of information, while vicarious experiences are less

286 dependable. Alfie recalled a mountaineering experience and said that 'having reached the

287 summit by the North Ridge is good for [my] confidence', because his personal goal had been

288 achieved. Dorothy reported that her coach 'is here telling us it's fine', giving a clear example

289 of verbal reassurance. Reuben highlighted the value of vicarious experiences and stated that

290 the coaches 'recounted their own tales...that no matter what you are trying to do, you feel

291 that they have done it before'. Dorothy gained her confidence through reassurance, Alfie via

292 his accomplishments, and Reuben by engaging with his coach's prior experiences. Thus, each

293 client seemed to be able to source the information and confidence-building support they

294 needed from their coach.

The participants valued interpersonal skills highly, in common with perceptions of

296 good coaching found outside the ambit of adventure sports (Becker, 2009; Black \& Weiss,

297 1992; Côté \& Sedgwick, 2003; Curran, Hill, Hall, \& Jowett, 2015). Sixty-nine respondents

298 ranked this aspect of coaching behaviour as the most important $(\mathrm{m}=23.5)$. Rachael

299 highlighted the link between rapport and trust in the coaches' judgement and stated that a

300 'good relationship or rapport with the instructor [coach] is vital because you got to be able to

301 trust their judgement'. Pearce linked rapport with his learning and explained that 'rapport is 
so important for the development of skills', while Griff said that the coaches are 'making sure everyone is getting what they want from the course'. Griff highlighted the relationship between rapport and achieving the client's goals and their desired coaching experience (Eastabrook \& Collins, 2019). The coaches appear to be strategically using their rapport with their clients in a more sophisticated manner than previously reported by Gray and Collins (2016)

Participants in this study valued high levels of enthusiasm in their coaches, and it was the third-ranked aspect of coaching behaviour $(\mathrm{m}=20.4)$ in Part 2. Dennis broadly asserted

310 that his coach had 'got a really positive outlook on life coming through'. More specifically,

311 Kristian linked the coaches' enthusiasm to their coaching practice, stating that such

312 'enthusiasm for coaching was infectious', while Gemma declared that her coach 'loves being

313 outside'. This highlights that coaches were enthusiastic about their coaching and the given

314 adventure activity, demonstrating commitment and emotional investment in their clients'

315 development. Such attitudes affect both goal setting and client support in adventurous

316 contexts.

The coach's credibility as a coach and also a respected practitioner of adventure sports appears to be a unique aspect of adventure sports coaching practice, as this was not reported in the literature of traditional sports coaching. While this aspect was implicit in

320 Collins and Collins' findings (2012, 2016a), it was explicit in this study and was ranked fourth by the respondents in Part $2(\mathrm{~m}=15.8)$. Alfie would only receive coaching from someone if 'they have credibility' in his terms. While credibility is desirable, it is unclear

323 what makes a coach credible to clients, and thus, how it could be enhanced. Consequently,

324 this is an area that requires further investigation. 

for example, stated that 'a highly qualified coach can inspire you to continue learning'. The coaches' ability to be inspirational was ranked fifth $(\mathrm{m}=15.5)$ by the respondents. There are two aspects to being inspired in this context. Firstly, the client is inspired by the coach's performance, both as a coach and as a performer, a unique aspect of adventure sports coaches

330 (Collins \& Collins, 2012). The clients want their coach to genuinely enjoy their job as this enhances the coaching experience for the client (Eastabrook and Collins, 2019). The second is routed in the developmental goals of the coaching. Inspired clients may be more likely to practice and thus to continue their development independently.

\section{Capacity to adapt}

The coaches' capacity to individualise the whole coaching experience was a key factor in the perception of good coaching by the participants in this study. Individualisation was ranked highest by 168 respondents in Part $2(\mathrm{~m}=24.5)$. Individualisation in this context was multifaceted and extended beyond the teaching of individual aspects of a sport, as reported by Ives (2008). For example, Dorothy highlighted the coaches' ability to identify the correct starting point of the coaching process via observation and questioning and stated that 'the coaches are so great at building on where you are as an individual'. Alfie said that his coach was able to give him 'space to work it out, so I'm not just remembering something they've said, I'm actually understanding'. This latter point from Alfie highlights his desire for the coach to align their teaching with how Alfie wants to learn at that point. Jack linked individualisation to risk tolerance, stating that ' $[\mathrm{I}]$ achieved something I wouldn't have done if he [the coach] hadn't been there', thus linking individualisation back to the development of confidence highlighted earlier. Jack would not otherwise have attempted the activity because of his perception of the involved risk and level of challenge that creates. Additionally and uniquely, individualisation was extended to the participants' conceptualisation of adventure 
350 (see Mackenzie \& Brymer, 2018) by the coaches. Dennis explained that the coaching he

351

352

353

354

355

356

357

358

359

360

361

362

363

364

365

366

367

368

369

370

371

372

373

374 received allowed him to no longer be 'at the behest of other people's plans', giving him the freedom to make his own decisions regarding his own participation and adventurous experiences.

Jack 'wanted to be imparted knowledge by someone who has been there, done it and knows what they are on about'. The coaches' depth of knowledge was clearly linked with credibility, as cited earlier, and it was ranked as the second most important factor in Part 2 (m $=23.5)$. Such a desire is common in cases of good coaching within other sports, as identified by multiple authors (Côté et al., 1995; Light \& Evans, 2013; Nelson et al., 2006). Two additional aspects of the adventure sport coaches' knowledge could be identified: (1) the desire for more knowledge stems from a desire to be independent of coaches, and (2) the coaches are expected to have knowledge of the hyper-dynamic context of their coaching. Tommy exemplified the former: 'when you are doing that on your own, you have to dig from your own experience and knowledge base in order to make that decision'. Moreover, Kristian noted that a good coach has 'been there and can take you to interesting places'. Lori highlighted that participations expect the coaches to have knowledge regarding the environment and coaching, building on their own experiences. This echoes the assertions of Collins et al. (2016), that a coach's knowledge gathered from experience and reflection is critical.

The coaches' ability to observe and analyse was ranked third within the high-order theme $(\mathrm{m}=19.9)$ and was an integral aspect of the individualisation of the coaching process. Alfie expected his coach to observe with 'a critical eye and analyse what you are doing and be able to pick up what you are doing wrong'. The participants wanted their coach to act as a critical friend. This highlights the need for coach and client to be in alignment with regard to the client's long-term goals. 
Participants valued coaches with a broad range of coaching strategies, ranking this

376

377 aspect as fourth in Part $2(\mathrm{~m}=17.3)$. Dennis appreciated his coach as he 'explained something in multiple different ways' and stated? the rest of the group also valued this. Meanwhile, Alfie noted that his coach was able to offer a more difficult route up to the summit that was their goal 'rather than picking an easier route' for the whole group. Clearly, in this case the coach sought to employ several practical strategies to achieve the same goal while also maintaining client security, demonstrating highly individualised and sophisticated judgement.

Dennis expected his coach to find out 'what are his aspirations, what can he do, [then] modify the course' to suit him, and a flexible programme was ranked fifth in terms of importance by the respondents in Part $2(\mathrm{~m}=17.1)$. Indeed, flexibility is required both on the part of coaches and their employers/organisations. To meet the aspirations of participants, coaches need to be adaptable within a flexible infrastructure. Additional resources such as transport, extra coaches, or indoor facilities may also be required to this end. However, highly qualified coaches and logistical support for the desired flexibility may have costrelated implications for coaches and their employers, and such options may not always be feasible during a single-course programme.

\section{Attributes of a good adventure sports coach}

Participants in this study valued the coaches' ability to enhance the coaching experience (Eastabrook \& Collins, 2019) by utilising a range of nuanced behaviours. The respondents had an expectation of a thorough coaching process distinct from a guided or led experience. People seeking coaching in any sport want their coaches to have the capacity to adapt in response to their learning needs and the environmental demands. However, the highorder themes indicate that three aspects specifically characterise good adventure sports 
coaches: knowledge of the environment, the extent and nature of individualisation, and the

400 coach's ability to act as a source of confidence. These aspects extend beyond the descriptors

401 for good coaching in other sports and given the importance placed on these attributes by the

402 participant mean that these could be considered unique to adventure sports coaching.

\section{$403 \quad$ Knowledge of the adventure environment}

It seems critical that coaches possess in-depth knowledge of the adventure sports coaching environment. There are three aspects to the coaching environment. The coaches need to understand the practicalities of coaching in adventurous environments, including where to go, the impact of the weather and its impact (see Aadland, Vikene, Varley and Moe (2017) as an example). Coaches need to be sensitive to the social and cultural environment that is desired by participants of adventure (see Lorimer and Holland-Smith (2012) as an example). This goes beyond merely understanding the dynamic environment as an adventure sport participant and includes how the environment interacts with a task and the individual.

412 The participants expect this knowledge to stem from a coach's extensive experience of the activity and environment. This environmental knowledge extends beyond simple situation awareness as described by Endsley (1997) into the comprehension of the factors causing the situation and an ability to project its implications on the students' learning, however specific research into this is required to more fully understand this aspect of the adventure sport

417 coaches knowledge.

\section{Expansive individualisation of the coaching and adventure experience}

The notion of individualisation in adventure sports extends beyond the teaching of technical skills and encompasses the client's perception of good teaching. This involves being able to coach in a way that aligns with clients' perceptions of good teaching to gain their trust and build rapport before exploring more sophisticated approaches to improving 
423 their performance. Closely linked to this is the coaches' tolerance of risk, which allows them

424 to manage the risk-versus-benefit decisions lying at the heart of coaching in this sector

425 (Collins \& Collins, 2013) by comprehending the concomitant potential benefits to students'

426 and clients' conceptualisation of participation: specifically, how they want to participate. The

427 latter aspect might include, for example, whether clients are more interested in developing

428 their technical abilities to deal with more challenging environments or in reaching a technical

429 level that satisfies their desired engagement with the wilderness (Eastabrook \& Collins,

430 2019).

431 An explicit development of confidence

Participants expect coaches to act as a source of confidence, with an appropriate level

of challenge is required for the activity to feel authentic enough to achieve goal

434

accomplishment. This level must be judged carefully by the coach, similar to the risk-versus-

benefit decision cited above. The participants in this study reported their coaches' use verbal

reassurance in their abilities, vicarious experiences lived via the coach, and the coaches'

437

personal accomplishments are helpful for achieving their goals and aspirations. These

438 strategies develop self-efficacy (Bandura, 1977).

\section{Limitations and future research}

As reported by Weiss et al. (1991), there is an inherent issue with clients' perceptions

441 of good coaching: namely, coaches who say nice things to participants might make them feel

442 good, but that is not necessarily good coaching. Similarly, 'good' coaching is a subjective

443 term. This subjectivity raises the question of whether what is perceived as good coaching

444 within a commercial setting, i.e., happy, repeat clients, is the same as what is perceived as

445 good coaching in a developmental context. Both contexts are valuable but are not separated

446 in this study, thereby presenting the contentious issue of commodification in adventure sports 
447 (see Beedie \& Hudson, 2003; Loynes, 1998; Varley, 2006). The commodification of

448 adventure sports opens a further line of enquiry to understand how commodification affects

449 coaching practice. Additionally, these findings only reflect a sample of British people's

450 perception of good coaching. Therefore, to further understand the perceived attributes of

451 good adventure sports coaches, it seems logical to extend the study size and location. It is a

452 further point of inquiry as it is not clear how coaches develop these attributes, as they do not

453 appear to be aspects of national governing adventure sports coach education. If national

454 governing bodies recognise the need for the attributes detailed in this study, then it seems

455 logical that a further study may be required to determine how these can be developed in

456 novice coaches.

\section{Conclusion}

The findings demonstrate that many of the participants' perceptions of good coaching are common to both adventure and traditional sports. However, importantly this study also provides evidence for three key attributes that are particularly critical for and pertinent to adventure sport coaches: (1) a rich and in-depth knowledge of the dynamic coaching environment and how it interacts with the individual; (2) an explicit, highly individualised approach that includes clients' conceptualisation of their participation in adventure sports; and (3) an ability to act on and develop participants' confidence. These perceptions present challenges for the adventure sport coach. Clearly the coach must fully comprehend the learners' needs and motivations. To meet them, be able to employ a range of technical and teaching strategies, and significantly, to have a full understanding of the adventurous setting. These findings offer a different perspective on adventure sport coaching and the way in which coaches might be trained and evaluated. Specifically, measuring coaching beyond the measurement of performance in a traditional sense. Which in turn does demonstrate a need for further research regarding performance in adventure sports. Furthermore, these findings 
strengthen the need for further research to investigate how adventure sport coaching knowledge, adventure sport individualisation and confidence is developed for future explicit inclusion in coach education and development.

\section{Disclosure statement}

No potential conflict of interest was reported by the authors.

\section{References}

Aadland, E., Vikene, O. L., Varley, P., \& Moe, V. F. (2017). Situation awareness in sea kayaking: towards a practical checklist. Journal of Adventure Education and Outdoor Learning, 17(3), 203-215. https://doi.org/10.1080/14729679.2017.1313169

Ahern, K. J. (1999). Ten Tips for Reflexive Bracketing. Qualitative Health Research, 9(3), 407-411. https://doi.org/10.1177/104973239900900309

Bandura, A. (1977). Self-efficacy: Toward a unifying theory of behavioral change. Psychological Review, 84(2), 191-215. https://doi.org/10.1037/0033-295X.84.2.191

Becker, A. J. (2009). It's Not What They Do, It's How They Do It: Athlete Experiences of Great Coaching. International Journal of Sports Science \& Coaching, 4(1), 93-119. https://doi.org/10.1260/1747-9541.4.1.93

Beedie, P., \& Hudson, S. (2003). Emergence of mountain-based adventure tourism. Annals of Tourism Research, 30(3), 625-643. https://doi.org/10.1016/S0160-7383(03)00043-4

Black, S. J., \& Weiss, M. R. (1992). The relationship among perceived coaching behaviors, perceptions of ability, and Motivation in competitive age-group swimmers. Journal of Sport \& Exercise Psychology, 14, 309-326. https://doi.org/10.1123/jsep.14.3.309

Bloom, G. A., Crumpton, R., \& Anderson, J. E. (1999). A systematic observation study of the 

teaching behaviors of an expert basketball coach. / Une etude d'observation systematique des comportements pedagogiques d'un entraineur expert de basketball. Sport Psychologist, 13(2), 157-170. https://doi.org/10.1123/tsp.13.2.157

Braun, V., \& Clarke, V. (2012). Thematic analysis. In Cooper H (Ed.), APA handbook of research methods in psychology. (2nd ed.). American Psychological Association.

Buckley, R. (2012). Rush as a key motivation in skilled adventure tourism : Resolving the risk recreation paradox. Tourism Management, 33(4), 961-970. https://doi.org/10.1016/j.tourman.2011.10.002

Cassidy, T., Jones, R. L., \& Potrac, P. (2009). Understanding sports coaching: the social, cultural and pedagogical foundations of coaching practice (2nd Editio). Oxford, UK.: Routledge.

Christian, E., Berry, M., \& Kearney, P. (2017). The identity, epistemology and developmental experiences of high-level adventure sports coaches. Journal of Adventure Education and Outdoor Learning, 17(4), 1-14. https://doi.org/10.1080/14729679.2017.1341326

Christian, E., Hodgson, C. I., Berry, M., \& Kearney, P. (2019). It's not what, but where: how the accentuated features of the adventure sports coaching environment promote the development of sophisticated epistemic beliefs. Journal of Adventure Education and Outdoor Learning, O0(00), 1-13. https://doi.org/10.1080/14729679.2019.1598879

Collins, D., Collins, L., \& Carson, H. J. (2016). "If it feels right, do it”: Intuitive decision making in a sample of high-level sport coaches. Frontiers in Psychology, 7(APR), 1-10. https://doi.org/10.3389/fpsyg.2016.00504

Collins, L., \& Brymer, E. (2018). Understanding nature sports: a participant centred 
perspective and its implications for the design and facilitating of learning and performance. Annals of Leisure Research, $0(0), 1-16$. https://doi.org/10.1080/11745398.2018.1525302

Collins, L., Carson, H. J., \& Collins, D. (2016). Metacognition and professional judgment and decision making in coaching: Importance, application and evaluation. Human Kinetics in International Sport Coaching Journal, 3(3), 355-36. https://doi.org/10.1123/iscj.2016-0037

Collins, L., \& Collins, D. (2012). Conceptualizing the adventure-sports coach. Journal of Adventure Education \& Outdoor Learning, 12(1), 81-93. https://doi.org/10.1080/14729679.2011.611283

Collins, L., \& Collins, D. (2013). Decision Making and Risk Management in Adventure Sports Coaching. Quest, 65(1), 72-82. https://doi.org/10.1080/00336297.2012.727373

Collins, L., \& Collins, D. (2015). Integration of professional judgement and decision-making in high-level adventure sports coaching practice. Journal of Sports Sciences, 33(6), 622633. https://doi.org/10.1080/02640414.2014.953980

Collins, L., \& Collins, D. (2016a). Challenges in Adventures Sports Coaching. In B. Humberstone, H. Prince, \& K. A. Henderson (Eds.), Routledge International Handbook of Outdoor Studies. Oxford: Routledge. https://doi.org/10.4324/9781315768465.ch44

Collins, L., \& Collins, D. (2016b). Professional judgement and decision-making in adventure sports coaching: the role of interaction. Journal of Sports Sciences, 34(13), 1231-1239. https://doi.org/10.1080/02640414.2014.953980

538 Collins, L., Collins, D., \& Grecic, D. (2015). The epistemological chain in high-level adventure sports coaches. Journal of Adventure Education and Outdoor Learning, 15(3), 
541 Côté, J. (2006). The Development of Coaching Knowledge. International Journal of Sports Science \& Coaching, 1(3), 217-222. https://doi.org/10.1260/174795406778604609

543 Côté, J., \& Gilbert, W. (2009). An Integrative Definition of Coaching Effectiveness and Expertise. International Journal of Sports Science \& Coaching, 4(3), 307-323. https://doi.org/10.1260/174795409789623892

Côté, J., Saimela, J., Trudel, P., Baria, A., \& Russell, S. (1995). The Coaching Model: A Grounded Assessment of Expert Gymnastic Coaches’ Knowledge. Journal of Sport and Exercise Psychology, 17(1), 1-17. https://doi.org/10.1123/jsep.17.1.1

Côté, J., \& Sedgwick, W. A. (2003). Effective behaviors of expert rowing coaches : A qualitative Investigation of Canadian Athletes and Coaches. International Sports Journal, 7(1), 62-77.

Curran, T., Hill, A. P., Hall, H. K., \& Jowett, G. E. (2015). Relationships between the CoachCreated Motivational Climate and Athlete Engagement in Youth Sport. Journal of Sport and Exercise Psychology, 37(2), 193-198. https://doi.org/10.1123/jsep.2014-0203

Deakin, H., \& Wakefield, K. (2014). Skype interviewing: reflections of two PhD researchers. Qualitative Research, 14(5), 603-616. https://doi.org/10.1177/1468794113488126

Doyle, J. R., Green, R. H., \& Bottomley, P. A. (1997). Judging Relative Importance: Direct Rating and Point Allocation Are Not Equivalent. Organizational Behavior and Human Decision Processes, 70(1), 65-72. https://doi.org/10.1006/obhd.1997.2694 questionnaires. Journal of Advanced Nursing, 42(1), 57-63. 
563 Dunlock, H. L. (1993). Research Design : Descriptive Research Definitions of. Journal of Pediatric Oncology Nursing, 10(4), 154-157.

565 Eastabrook, C., \& Collins, L. (2019). Why do individuals seek out adventure sport coaching? Journal of Adventure Education and Outdoor Learning, 1-14.

Endsley, M. R. (1997). The role of situation awareness in naturalistic decision making. In C. Zsambok \& G. Klein (Eds.), Naturalistic decision making (pp. 269-284). New York: Psychology Press.

571

572

573

574

575

576

577

578

579

580

581

582

583

Fereday, J., \& Muir-Cochrane, E. (2006). Demonstrating Rigor Using Thematic Analysis: A Hybrid Approach of Inductive and Deductive Coding and Theme Development. International Journal of Qualitative Methods, 5(1), 80-92. https://doi.org/10.1063/1.2011295

Gearity, B. T. (2012). Poor teaching by the coach: A phenomenological description from athletes' experience of poor coaching. Physical Education and Sport Pedagogy, 17(1), 79-96. https://doi.org/10.1080/17408989.2010.548061

Gray, P., \& Collins, D. (2016). The adventure sports coach: all show and no substance? Journal of Adventure Education and Outdoor Learning, 16(2), 160-171. https://doi.org/10.1080/14729679.2015.1123163

Ianiro, P. M., Lehmann-Willenbrock, N., \& Kauffeld, S. (2015). Coaches and Clients in Action: A Sequential Analysis of Interpersonal Coach and Client Behavior. Journal of Business and Psychology, 30(3), 435-456. https://doi.org/10.1007/s10869-014-9374-5

Ives, Y. (2008). What is 'Coaching '? An Exploration of Conflicting Paradigms. International Journal of Evidence Based Coaching and Mentoring, 6(2), 100-113. 
Kerr, J. H., \& Mackenzie, S. H. (2012). Multiple motives for participating in adventure sports. Psychology of Sport and Exercise, 13(5), 649-657. https://doi.org/10.1016/j.psychsport.2012.04.002

Lafrenière, M. A. K., Jowett, S., Vallerand, R. J., \& Carbonneau, N. (2011). Passion for coaching and the quality of the coach-athlete relationship: The mediating role of coaching behaviors. Psychology of Sport and Exercise, 12(2), 144-152. https://doi.org/10.1016/j.psychsport.2010.08.002

Light, R. L., \& Evans, J. R. (2013). Dispositions of elite-level Australian rugby coaches towards game sense: Characteristics of their coaching habitus. Sport, Education and Society, 18(3), 407-423. https://doi.org/10.1080/13573322.2011.593506

Lincoln, Y., \& Guba, E. (2005). Paradigmatic controversies, contradictions, and emerging 598 confluences. In N. K. Denzin \& Y. S. Lincoln (Eds.), The Sage handbook of qualitative research (pp. 191-215). Thousand Oaks, CA: Sage Publications Ltd.

Lorimer, R., \& Holland-Smith, D. (2012). Why Coach? A Case Study of the Prominent 601

602 Influences on a Top-Level UK Outdoor Adventure Coach. The Sport Psychologist,

Loynes, C. (1998). Adventure in a Bun. Journal of Experiential Education, 21(1), 35-39.

Mackenzie, S. H., \& Brymer, E. (2018). Conceptualizing adventurous nature sport: A positive psychology perspective. Annals of Leisure Research, $0(0), 1-13$.

606 https://doi.org/10.1080/11745398.2018.1483733

Mageau, G. A., \& Vallerand, R. J. (2003). The coach-athlete relationship: A motivational 608 model. Journal of Sports Sciences, 21(11), 883-904. 
McElligott, S. (2015). Overseas Expeditions : Self-Esteem and Transformational Leadership. University of Bangor, UK.

612 Nash, C., Martindale, R., Collins, D., \& Martindale, A. (2012). Parameterising expertise in 613 coaching: Past, present and future. Journal of Sports Sciences, 30(10), 985-994.

$614 \quad$ https://doi.org/10.1080/02640414.2012.682079

615 Nelson, L. J., Cushion, C. J., \& Potrac, P. (2006). Formal, Nonformal and Informal Coach 616 Learning: A Holistic Conceptualisation. International Journal of Sports Science \& 617 Coaching, 1(3), 247-259. https://doi.org/10.1260/174795406778604627

618 O'Keefe, L. (2019). Active Lives Adult Survey 17/18 Report. Sports England.

619 Ojala, A., \& Thorpe, H. (2015). The Role of the Coach in Action Sports : Using a Problem620 based Learning Approach A Case in Point : International Sport Coaching Journal, 2, 621 64-71. https://doi.org/10.1123/iscj.2014-0096

622 Pomfret, G., \& Bramwell, B. (2016). The characteristics and motivational decisions of 623 outdoor adventure tourists: a review and analysis. Current Issues in Tourism, 19(14), 1447-1478. https://doi.org/10.1080/13683500.2014.925430

Price, M. S., \& Weiss, M. R. (2013). Relationships among coach leadership, peer leadership, and adolescent athletes' psychosocial and team outcomes: A test of transformational leadership theory. Journal of Applied Sport Psychology, 25(2), 265-279.

628 https://doi.org/10.1080/10413200.2012.725703

Robson, C. (2011). Real World Research (3rd ed.). Chichester: Wiley.

630 Sage, G. H. (1973). The coach as management: Organizational leadership in American sport. 
632 Saury, J., \& Durand, M. (1998). Practical knowledge in expert coaches: On-site study of 633 coaching in sailing. Research Quarterly for Exercise and Sport, 69(3), 254-266.

634 https://doi.org/10.1080/02701367.1998.10607692

635 Schommer, M. (1994). Synthesizing epistemological belief research: Tentative

636

637 understandings and provocative confusions. Educational Psychology Review, 6(4), 293319. https://doi.org/10.1007/BF02213418

638

Sinfield, D., Allen, J., \& Collins, L. (2019). A comparative analysis of the coaching skills

640

641 required by coaches operating in different non-competitive paddlesport settings. Journal

Sinickas, A. (2007). Finding a Cure for Survey Fatigue. Strategic Communication of Adventure Education and Outdoor Learning, 00(00), 1-15. https://doi.org/10.1080/14729679.2019.1609998

644 Smith, B., \& McGannon, K. R. (2018). Developing rigor in qualitative research: problems 645 Management, 11(2), 11.

Smith, J. A., Larkin, M., \& Flowers, P. (2009). Interpretative Phenomenological Analysis: Understanding Method and Application. London: Sage.

650 Stoszkowski, J., \& Collins, D. (2012). Communities of practice, social learning and 651 networks: exploiting the social side of coach development. Sport, Education and Society, 19(9), 773-788. https://doi.org/10.1080/13573322.2012.692671 within outdoor and expedition leaders. Journal of Adventure Education \& Outdoor 
656 Varley, P. (2006). Confecting Adventure and Playing with Meaning: The Adventure

657 Commodification Continuum. Journal of Sport \& Tourism, 11(2), 173-194.

$658 \quad$ https://doi.org/10.1080/14775080601155217

659 Vella, S. a., Oades, L. G., \& Crowe, T. P. (2012). Validation of the differentiated

660 transformational leadership inventory as a measure of coach leadership in youth soccer.

$661 \quad$ Sport Psychologist, 26(2), 207-223. https://doi.org/10.1123/tsp.26.2.207

662 Weiss, M. R., Barber, H., Sisley, B. L., \& Ebbeck, V. (1991). Developing competence and 663 confidence in novice female coaches: II. Perceptions of ability and affective experiences 664 following a season-long coaching internship. Journal of Sport \& Exercise Psychology, $665 \quad 13(4), 336-363$.

666 Zhang, Y., \& Wildemuth, B. M. (2006). Unstructured interviews. Applications of Social 667 Research Methods to Questions in Information and Library Science, (1998), 222-231.

668 Zoharbi, M. (2016). Mixed Method Research: Instruments, Validity, Reliability and 669 Reporting Findings. Theory and Practice in Language Studies, 3(2), 254-262.

670

671 
673 Semi-structured interview guide sheet

\begin{tabular}{lll}
\hline Initial Question & Secondary Question & Prompts
\end{tabular}

Administration

Questions

Signed consent

Remind interviewee they are

free to withdraw at any time

Can you tell me about your most recent coaching session?

Where did it take place?

Location

Who was it with?

Duration

What was the best part?

Commercial operator

What did you expect from the overall experience?

Any learning objectives?

TTPP

Experiencing any specific

Enjoyment

issues?

Culture of adventure

New challenge or

environments?

How did the coach meet your expectations?

How friendly was the coach or

Quality of resources their warmth of welcome? Teaching ability

Was there a personalised plan for the course?

The technical ability

What activities did you of the coach undertake?

How important was it that the coach took you on a real adventure?

Where did the coaching take place?

Challenge 
Did you feel comfortable in the Learning places you went to? opportunities

Do you feel more able to re- Self-belief visit those places postcoaching?

Self-efficacy

Adventure

What did the coach do to aid your long-term learning aspirations?
Do you have a specific action Independence plan to follow?

What do you still need to practice?

What adventures can you now have?
Self-directed learning

Environments

Challenges

Venues

Community of practice 
676 Table 2

677 Thematic analysis of the semi-structured interviews

\begin{tabular}{ll}
\hline $\begin{array}{l}\text { High-Order } \\
\text { Themes (2) }\end{array}$ & Mid-Order Themes (10) \\
\hline Coaching behaviour & Coach is the source of confidence \\
& Interpersonal skills \\
Coach's enthusiasm & Coach was inspirational \\
Coach has high credibility \\
Individualised approach \\
Adaptive course programme \\
Observation and analysis \\
Coach's depth of knowledge \\
Range of coaching strategies
\end{tabular}

678

679 
681 Descriptive data analysis of the survey, displaying relative importance of mid-order themes

\begin{tabular}{|c|c|c|c|c|}
\hline High-Order Theme & Mid-Order Theme & Mean & SD & Skew \\
\hline \multirow[t]{5}{*}{ Coaching behaviour } & Coach is the source of confidence & 24.9 & 11.2 & 0.7 \\
\hline & Interpersonal skills & 23.5 & 10.3 & 1.8 \\
\hline & Coach's enthusiasm & 20.4 & 7.2 & 0.6 \\
\hline & Coach has high credibility & 15.8 & 8.9 & 0.6 \\
\hline & Coach is inspirational & 15.5 & 7.9 & 0.7 \\
\hline \multirow[t]{5}{*}{ Capacity to adapt } & Individualised approach & 24.5 & 9.9 & 1.3 \\
\hline & Coach's depth of knowledge & 21.2 & 9.7 & 1.9 \\
\hline & Observation and analysis & 19.9 & 7.6 & 0.7 \\
\hline & Range of coaching strategies & 17.3 & 7.2 & -0.4 \\
\hline & Adaptive course programme & 17.1 & 7.3 & 0.2 \\
\hline
\end{tabular}

682

683 